\title{
Refletindo sobre corpo, gênero e sexualidade através de proposição arte/educativa
}

\author{
Reflexión sobre el cuerpo, el género y la sexualidad a través de la \\ propuesta de arte / educativa
Reflecting on body, gender and sexuality through art / educational proposition

\author{
Laura Sacco dos Anjos Torres ${ }^{1}$ \\ Maristani Polidori Zamperetti ${ }^{2}$
}

\begin{abstract}
Resumo
Este trabalho tem como objetivo destacar as representações de gênero presentes nas produções de alunxs desenvolvidas a partir de uma proposta arte/educativa que versava sobre consumo, estando este texto inserido no projeto de pesquisa Proposições arteleducativas e educação do sensível: interlocuções sobre o consumo. Assim, são problematizadas representações de gênero através da compreensão crítica da cultura visual em que os sentidos são construídos culturalmente, apresentando-se a interpretação enquanto prática social. Entende-se que as interrelações entre corpo, consumo e sexualidade são evidenciadas nos discursos propiciados através de anúncios publicitários. Nesse processo, encontram-se imbricadas relações de desigualdade social, bem como as relativas a gênero. Além da discussão a respeito dos anúncios publicitários, foram apresentadas obras de arte que viabilizam refletir sobre as questões de aquisição de produtos e suas relações com cultura, sociedade e identidade. Desse modo, a questão das visualidades é pensada juntamente com o discurso como unidade de análise para os sentidos e interações que se estabelecem, sendo utilizado como referencial teórico a perspectiva dialógica bakhtiniana. Desenvolver propostas arte/educativas em que o corpo está integrado é, portanto, um meio de problematizar questões relativas à identidade.
\end{abstract}

Palavras-Chave: Corpo; cultura visual; ensino da arte; gênero; identidade.

\section{Resumen}

Este trabajo tiene como objetivo destacar las representaciones de género presentes en las producciones de alunxs desarrolladas a partir de una propuesta arte / educativa que versaba sobre consumo, estando este texto insertado en el proyecto de investigación Propuestas de arte / educación y educación de lo sensible: interlocuciones sobre el consumo. Así, son problematizadas representaciones de género a través de la comprensión crítica de la cultura visual en que los sentidos se construyen culturalmente, presentándose la interpretación como práctica social. Se entiende que las interrelaciones entre cuerpo, consumo y sexualidad se evidencian en los discursos propiciados a través de anuncios publicitarios. En ese proceso, se encuentran imbricadas relaciones de desigualdad social, así como las relativas a género. Además de la discusión acerca de los anuncios publicitarios, se presentaron obras de arte que viabilizaban reflexionar sobre las cuestiones de adquisición de productos y sus relaciones con cultura, sociedad e identidad. De ese modo, la cuestión de las visualidades es pensada junto con el discurso que es unidad de análisis para los sentidos e interacciones que se establecen, siendo utilizado como referencial teórico la perspectiva dialógica bakhtiniana. Desarrollar propuestas arte / educativas en las que el cuerpo está integrado es, por lo tanto, un medio de problematizar cuestiones relativas a la identidad.

Palabras claves: cuerpo; cultura visual; enseñanza del arte; género; identidad.

\footnotetext{
${ }^{1}$ Mestranda em Educação pelo Programa de Pós-Graduação da Universidade Federal de Pelotas (UFPEL) Faculdade de Educação; Pelotas: Rio Grande do Sul, Brasil; laura.torres.sat@gmail.com.

2 Doutora em Educação pelo Programa de Pós-Graduação da Universidade Federal de Pelotas (UFPEL) Faculdade de Educação; Pelotas: Rio Grande do Sul, Brasil; maristaniz@ hotmail.com.
} 


\begin{abstract}
This work aims to highlight the representations of genres present in the productions of leaners developed from an Art Educational proposal that dealt with consumption, being this text inserted in the research project Proposals for art / education and education of the sensitive: dialogues on consumption. Thus, gender representations are problematized through the critical understanding of the visual culture in which the senses are culturally constructed, presenting the interpretation as a social practice. It is understood that the interrelationships between body, consumption and sexuality are evidenced in the speeches offered through commercials. In this process, relations of social inequality as well as those related to gender are imbricated. In addition to the discussion about advertisements, works of art have been presented that enable us to reflect on the issues of product acquisition and their relationship with culture, society and identity. In this way, the question of visualities is thought together with the discourse that is the unit of analysis for the senses and interactions that are established, the theoretical Bakhtinian perspective being used as theoretical reference. Developing Art Educational proposals in which the body is integrated is, therefore, a means of problematizing issues related to identity.
\end{abstract}

Keywords: Body; genre; identity; teaching of art; visual culture.

\title{
1. Introdução
}

O presente trabalho surgiu de uma proposta arte/educativa que versava sobre imaginário de consumo, estando vinculado ao projeto de pesquisa Proposições arteleducativas e educação do sensível: interlocuções sobre o consumo que tem como objetivo geral verificar as interlocuções que foram possibilitadas através de proposta arte/educativa. Assim sendo, essa pesquisa possuí abordagem qualitativa analítico exploratória, do tipo estudo de caso.

Desse modo, salienta-se que as questões relativas a gênero surgiram como aspectos transversais à prática, visto que o foco da atividade estava em aspectos relativos ao consumo e às interlocuções estabelecidas entre professora e alunos. A proposta foi desenvolvida ao dia sete de dezembro de 2017 através do Programa Institucional de Iniciação à Docência (PIBID) em uma escola municipal de Pelotas, tendo como público alvo jovens com faixa etária de doze a dezessete anos.

Assim, as questões de gênero se veem vinculadas às relativas a identidade, o que faz com que surjam elementos pertinentes através dos relatos dos alunos e de suas produções. Conforme Freedman (1984), apesar de os estudantes estarem constantemente dispostos a um amplo universo imagético, não estão preparados para refletir como essas visualidades agem no sentido de construir a sua identidade. Em sala de aula, percebeu-se que devido a turma apresentar um público bastante heterogêneo, alguns estudantes estavam mais inclinados a realizar interpretações críticas, através da análise de imagens e de enunciados por meio de artefatos da Cultura Visual, em relação a outros. Logo, torna-se necessário que os arte/educadores proponham questões criativas que auxiliem os alunos a compreender questões de ordem social e cultural, vinculadas à identidade. 
Compreende-se que aspectos relativos à identidade de gênero foram pensados de maneira gradativa através da leitura textual e da compreensão crítica imagética de elementos que transcendem os aspectos formais da semiótica, estando esses atrelados a relações culturais.

\section{Metodologia}

Foi utilizada metodologia interdisciplinar em ensino de Artes, sendo compreendidos aspectos da cultura visual enquanto vinculadores de sentido para a proposição arte/educativa desenvolvida.

A proposta arte/educativa compreendeu os seguintes momentos: em um primeiro momento, foi realizada dinâmica através da leitura do poema Eu, etiqueta de Carlos Drummond de Andrade; em um segundo momento, análise de obras artísticas com temática voltada para o imaginário de consumo; em um terceiro momento, análise de anúncios publicitários; e, por último, a produção de etiquetas pelos alunos.

$\mathrm{O}$ ato de propor uma leitura em que os interlocutores ficassem dispostos em pé e de maneira circular tratou-se de uma estratégia para que se fixasse melhor a atenção ao que estava inscrito no poema, sendo realizada uma leitura dialogada, consultando-se dúvidas referentes ao vocabulário. Além de ser considerado uma estratégia, o modo de realização da leitura torna explícita a questão de a corporeidade estar intrinsicamente associada à Arte, sem que dela possa ser retirada. Assim, os alunos ficaram dispostos em duplas, realizando a leitura de fragmentos do poema seguindo ordenação conforme numeração inscrita no verso da etiqueta.

Em minha calça está grudado um nome Que não é meu de batismo ou de cartório Um nome... estranho
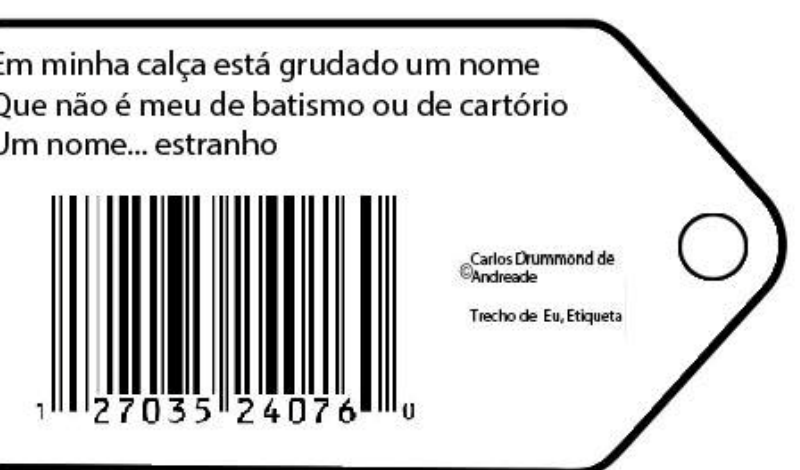

Figura 1: Material de autoria da graduanda, contendo fragmento do Poema Eu, Etiqueta em fragmentos. Fonte: Arquivo da pesquisadora, 2015.

A seleção do poema $E u$, etiqueta para uma abordagem inicial foi realizada em virtude de associar questões relativas ao consumo a aspectos referentes à identidade e ao corpo, o qual: 
[...] não existe a priori. Ao contrário, ele vai se formando, surgindo com o tempo, como resultado do ajustamento do organismo biológico aos modelos socioculturais de corpos masculinos e corpos femininos, estabelecidos pela sociedade de uma determinada época e lugar. Ninguém nasce com um corpo de homem ou de mulher: constrói-se um, aparentando ser um (LANZ, 2017, p. 136).

Desse modo, foi introduzida a reflexão sobre a conformidade ou não-conformidade aos papéis de gênero através de uma serigrafia intitulada Interior (Fig. 4), sendo gerada a proposição que serviu de embasamento para interpretação de uma segunda serigrafia do mesmo "O que tornam os nossos lares tão diferentes e atraentes?". Em sequência, foi perguntado se os alunos realmente acreditavam que aquele lar retratado na obra poderia ser entendido como atraente nos dias de hoje. Também se indagou qual o papel assumido por aquela figura feminina dentro do contexto remetido e representado pela obra.

Em resposta, os alunos manifestaram a opinião de que aquele lar não seria considerado atraente por apresentar uma televisão antiquada.

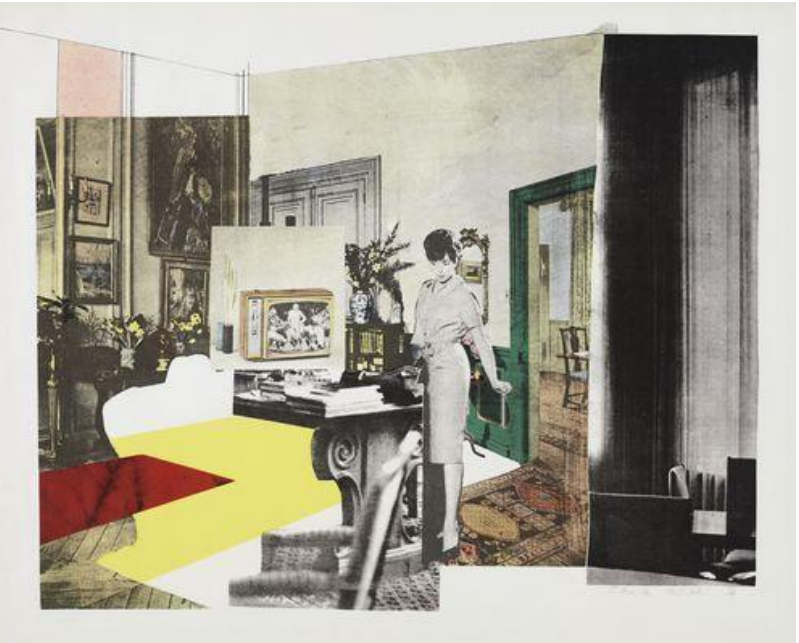

Figura 2: Richard Hamilton. Interior, 1964-1965. Serigrafia em papel. 49,5 cm x 63,8 cm. Fonte: AROUCA, 2012.

Além disso, uma das meninas abordou a questão do trabalho doméstico, comunicando que a figura feminina pareceria estar empurrando algum instrumento de limpeza. Ocorreu uma situação de embate, devido a colocações de alguns rapazes que afirmavam ser obrigação feminina o cuidado com o lar e a dedicação a tarefas domésticas. Foi abordado que esses cuidados independem de gênero e que esse posicionamento derivava de uma concepção machista de sociedade.

Salienta-se que essas reflexões surgiram dos próprios estudantes e dos embates estabelecidos em sala de aula, o que demonstra que “[...] a palavra é a arena onde se confrontam aos valores sociais contraditórios; os conflitos da linguagem refletem os conflitos de classe no interior mesmo do sistema: comunidade semiótica e classe social não se recobrem" (YANGUELLO, 2014, p.14). 
Nota-se que aspectos como o desenvolvimento da capacidade criativa, o estabelecimento de uma educação por vias do afeto só podem ser pensados mediante a interação com o outro. É através do outro que me constituo enquanto ser dotado de linguagem, visto que:

O sujeito se desenvolve nos conflitos e nas contradições que, por sua vez, são carregados de emoção. Essa condição lhe possibilita a construção do conhecimento e a ampliação de conceitos. A afetividade constitui um domínio funcional tão importante quanto o da inteligência e contribui de forma significativa para os processos motivacionais no contexto da educação. Ambas (afetividade e inteligência) têm funções diferenciadas e são dependentes em seu desenvolvimento, permitindo ao sujeito atingir níveis de evolução cada vez maiores e se completam numa dinâmica de interação (MEIRA, 2010, p. 20-21).

É no contexto escolar que se aprende a negociar, a discutir, a brigar, a reconsiderar, sendo esse âmbito marcado por uma série de fatores que ao sujeito lhe é disposta culturalmente e que propiciam normas para uma convivência mais harmônica em sociedade, ou pelo menos seriam esses alguns fatores que necessitariam ser trabalhados nas escolas. Conforme Duarte Jr (2000, p.86):

Saber argumentar, saber contar, narrar, prender o ouvinte e, sobretudo, saber ouvir o que ele tem a dizer só se aprende com alguma prática. Prática essa que, no entanto, parece cada vez mais ausente da vida cotidiana dos habitantes de nossa modernidade tardia, os quais, sem tempo a perder com essas "irrelevâncias", economizam a palavra para empregá-la preferencialmente naquelas situações "de negócio" ou estabelecidas institucionalmente, ou seja, naqueles momentos efetivamente lucrativos e utilitários. Parece que, cada vez mais, o verbo mostra-se ligado à verba.

Assim, imagens como as reproduzidas em sequência foram apresentadas aos alunos:

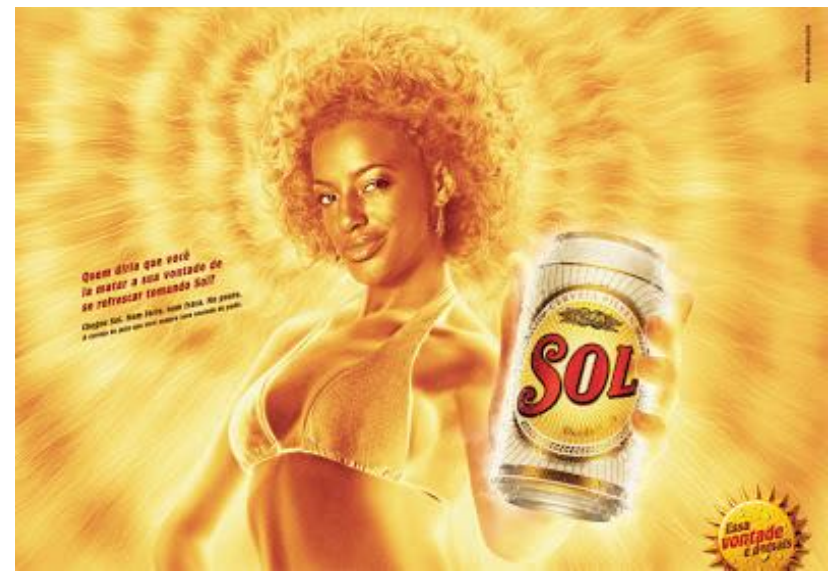

Figura 3: Anúncio publicitário da Cerveja Sol [Quem diria que você ia matar a sua vontade de se refrescar tomando Sol?]. Fonte: CERVEJA SOL, 2015. 


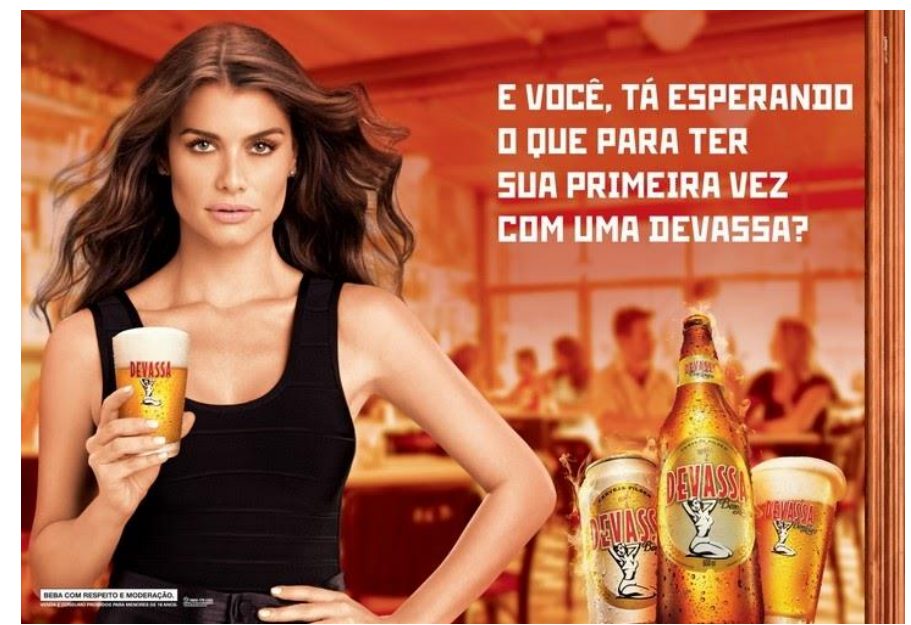

Figura 4: Anúncio publicitário da Cerveja Devassa. Fonte: CERVEJA DEVASSA, 2015.

Cabe ressaltar que, ao apresentar esses anúncios publicitários que retratavam a mulher em uma posição servil, logo de inferioridade, as meninas manifestaram-se contra essa objetificação, expressando discursos de emancipação feminina.

Anúncios publicitários como este foram colocados em justaposição com determinada obra de Barbara Kruguer (figura 5), tendo uma aluna indagado: "Sôra', isso aí tá falando daquelas 'parada' do feminismo?".

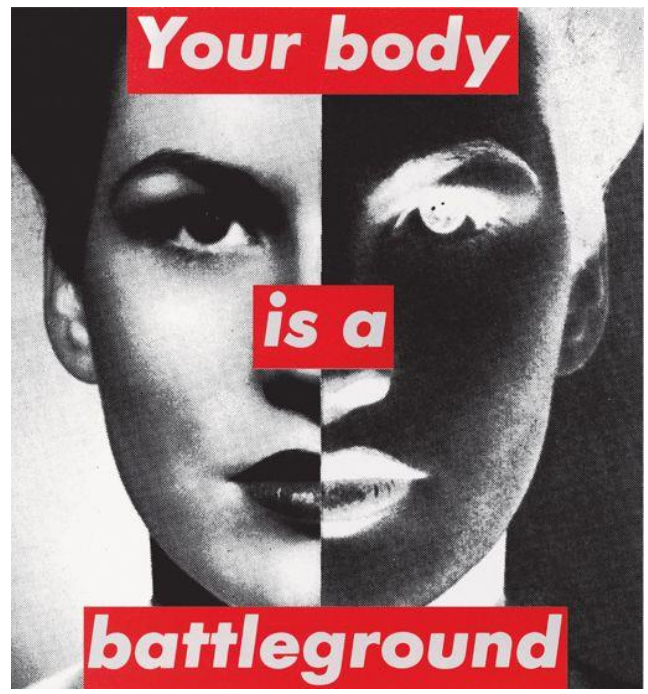

Figura 5: Barbara Kruguer. Your body is a battleground - "Seu corpo é um campo de batalha", 1984. Fonte: AROUCA, 2012

Durante a proposição arte/educativa, foi possível perceber o repertório que os estudantes possuíam, permitindo com que se os produtos culturais por eles consumidos fossem reconhecidos. Logo, tornou-se evidente o quanto os discursos sofrem interferência de gênero, e como a elaboração de um conjunto de imagens referenciais depende dessas questões.

\section{Resultados}


O corpus para análise se constituiu de 50 etiquetas produzidas pelos alunos em sala de aula. Para uma melhor interpretação dos dados, foi realizado um estudo classificatório em que se considera as etiquetas que repetem frases, reproduzem marcas e grifes, seguem a lógica pragmática e mercadológica a qual se destinam as etiquetas, criam novas marcas, contestam a lógica de mercado à medida que subvertem seu uso original, discutem questões de gênero, utilizam seu próprio nome. O quadro abaixo ilustra em uma análise numérica as classificações das etiquetas.

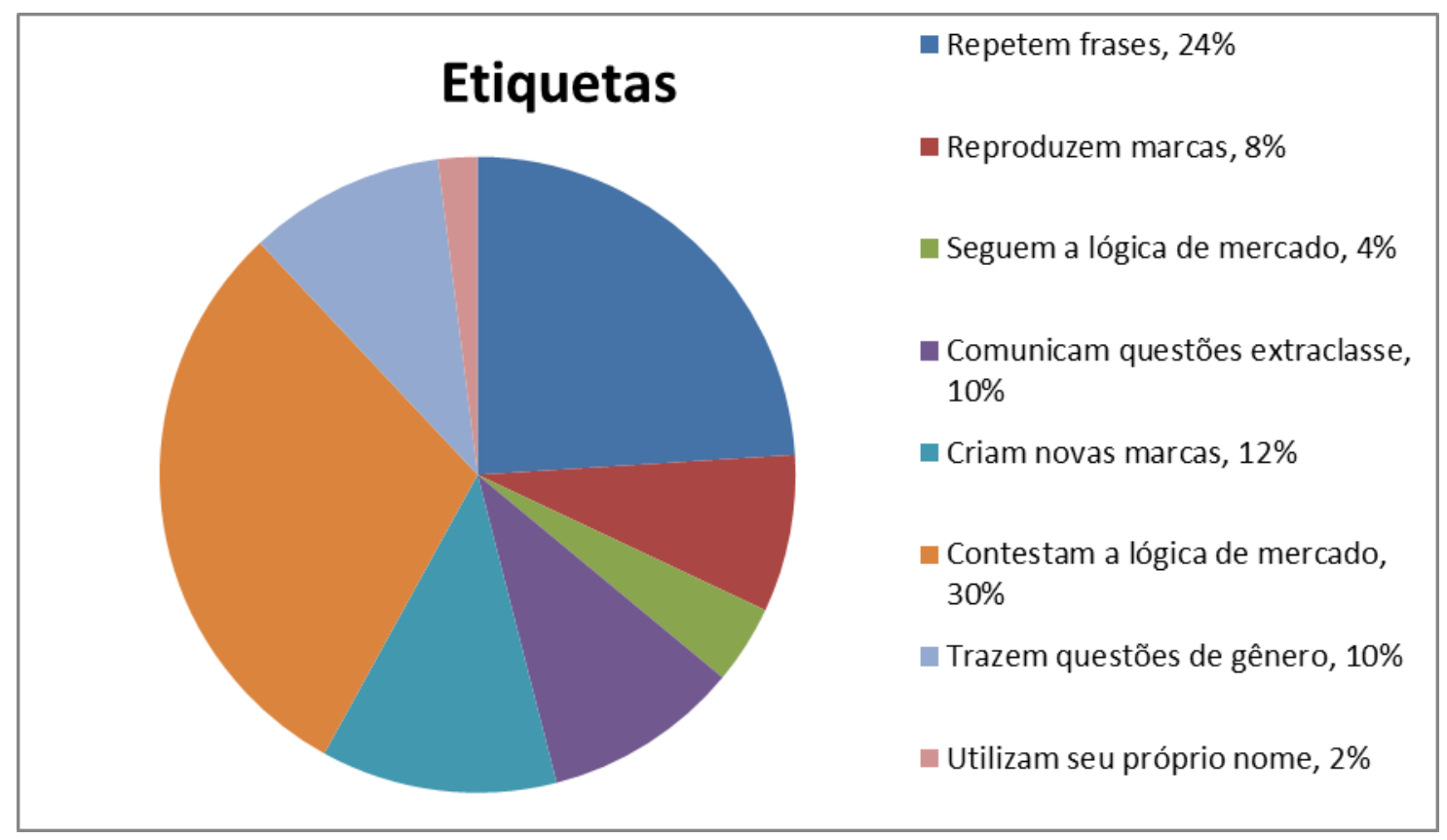

Gráfico 1: Resultados.

O trabalho que segue (figura 6) foi produzido por uma aluna que, ao ser indagada sobre as motivações de seu trabalho, respondeu: "Eu fiz esse desenho porque esse do desenho é o meu irmão. Minha mãe diz que por ele ser menino não precisa limpar a casa, nem 'ajudá' com as coisa de casa. Eu fico com raiva! Acho ruim. Isso é machismo, né, 'sôra'? Ele não é relaxado porque é guri, como a mãe diz, é porco porque a minha mãe e 'as mulher' da família fazem tudo pra ele. A minha mãe briga comigo porque eu acho que não sou obrigada a limpar a sujeira dele e não limpo, e digo pra ela que ele devia fazer as tarefas de casa que nem eu" (CADERNO DE CAMPO. ALUNA LUANA, 2017). ${ }^{3}$

\footnotetext{
${ }^{3}$ Os nomes aqui inscritos são fictícios dada a necessidade de preservar as identidades dos alunos.
} 


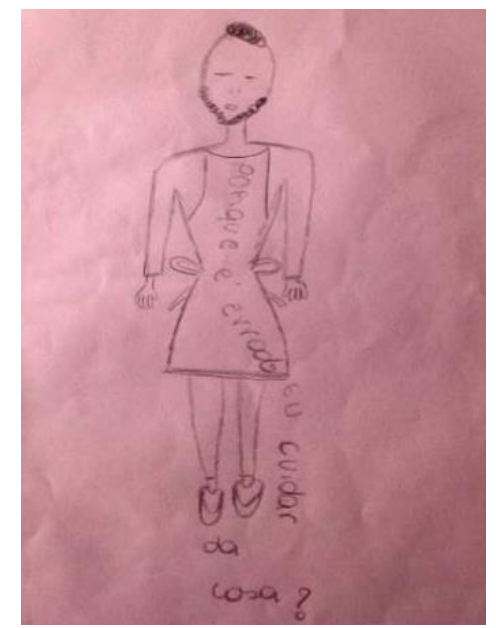

Figura 6: Desenho produzido por aluna de Ensino Fundamental, 2017. Fonte: Arquivo da pesquisadora.

No que concerne à próxima etiqueta a ser analisada, também produzida por uma aluna, a autora justificou sua escolha com essas palavras: "Porque é assim, 'sôra'! Ninguém tem direito de tocar ou passar a mão! Acontece em todos lugares, no ônibus, na escola... Deviam cobrar mais respeito 'dos guri'. Na escola, todo mundo finge que não vê nada.” (CADERNO DE CAMPO. ALUNA JOANA, 2017).

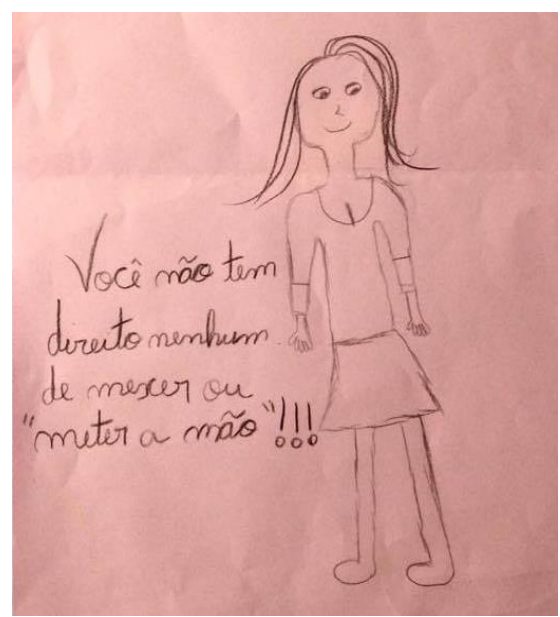

Figura 7: Desenho produzido por aluna de Ensino Fundamental, 2017. Fonte: Arquivo da pesquisadora.

A imagem a seguir foi produzida por um aluno que perguntou: “Ô, 'sôra', Girl Power significa meninas poderosas ou poderes das mulheres?"

Perguntou-se a ele qual uso julgava melhor: meninas empoderadas ou meninas poderosas, ou poder das meninas? (CADERNO DE CAMPO. ALUNO ROBERTO, 2017).

Ele riu e fez este desenho: 


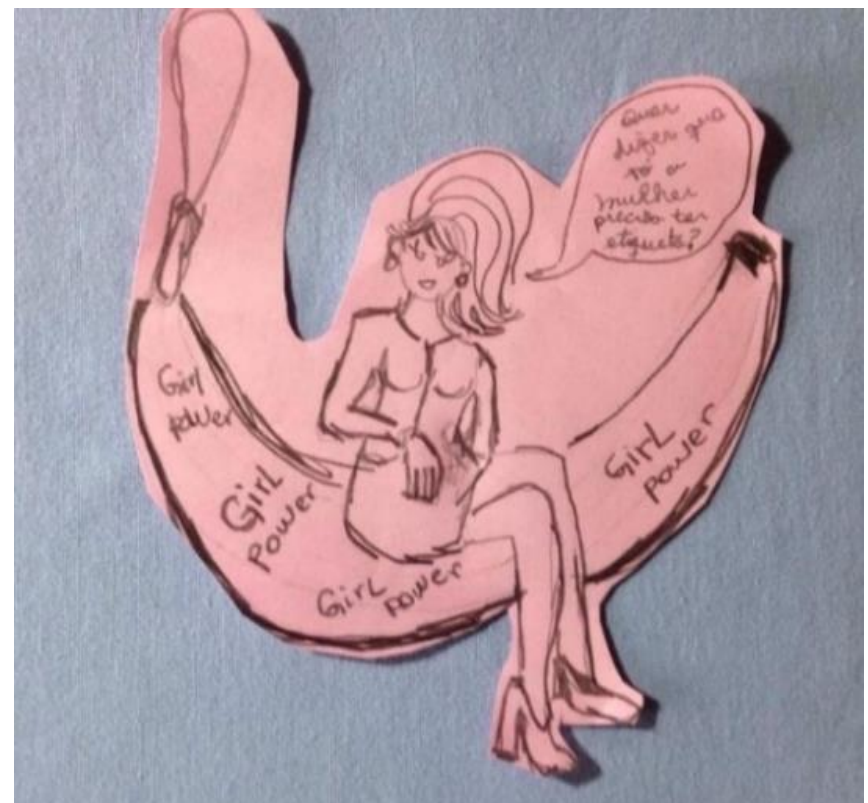

Figura 8: Desenho produzido por aluno de Ensino Fundamental, 2017. Fonte: Acervo da graduanda.

É perceptível que a imagem traz subjacente uma boa dose de ironia por parte do aluno ao colocar uma mulher representada, sentada em uma banana, na qual estão inscritos "Girl power" repetitivamente, sendo apresentada como fala da personagem a seguinte questão: "Quer dizer que só a mulher precisa ter etiqueta?"

Logo, está em evidência o jogo de sentidos estabelecido através da banana, que pode ser interpretada como uma alusão ao falo, objeto de diversas contestações quando se pondera a respeito das considerações de Freud (2010) no que tange à orientação sexual, bem como quando se parte dos pressupostos de Lacan (1998) sobre uma dada "identificação salutar" que estaria pautada na heterossexualidade. Assim, o poder estaria associado ao falo, entretanto os estudos de Lacan também apontam para a possibilidade de a mulher assumir posição fálica. Denota-se, através desses usos linguísticos, uma sobreposição de gênero. Essa primazia do falo e do heteronormativismo será questionada por Buttler (2003) que vai romper com binarismos e essencialismos propostos.

Conforme Tilio (2014, p. 131):

Em suma, tanto Freud como Lacan partem do pressuposto de que o pênis/falo é a norma orientadora da vida psíquica e que os homens, por possuírem pênis, possuiriam certas vantagens sobre as mulheres (invejosas do pênis e necessitadas de se ligarem a alguém que o possua) e que as identificações, para serem normais e salutares, devem seguir um padrão complementar calcado na heterossexualidade.

Seria interessante realizar associações entre o trabalho do aluno com a obra da artista gaúcha Zoravia Bettiol, justamente em virtude da variedade de significados incorporados pela representação de uma mulher sentada que, além de nos trazer à superfície uma série de 
discursos sobre o comportamento feminino, colocam em xeque os diversos sentidos evocados por essas representações.

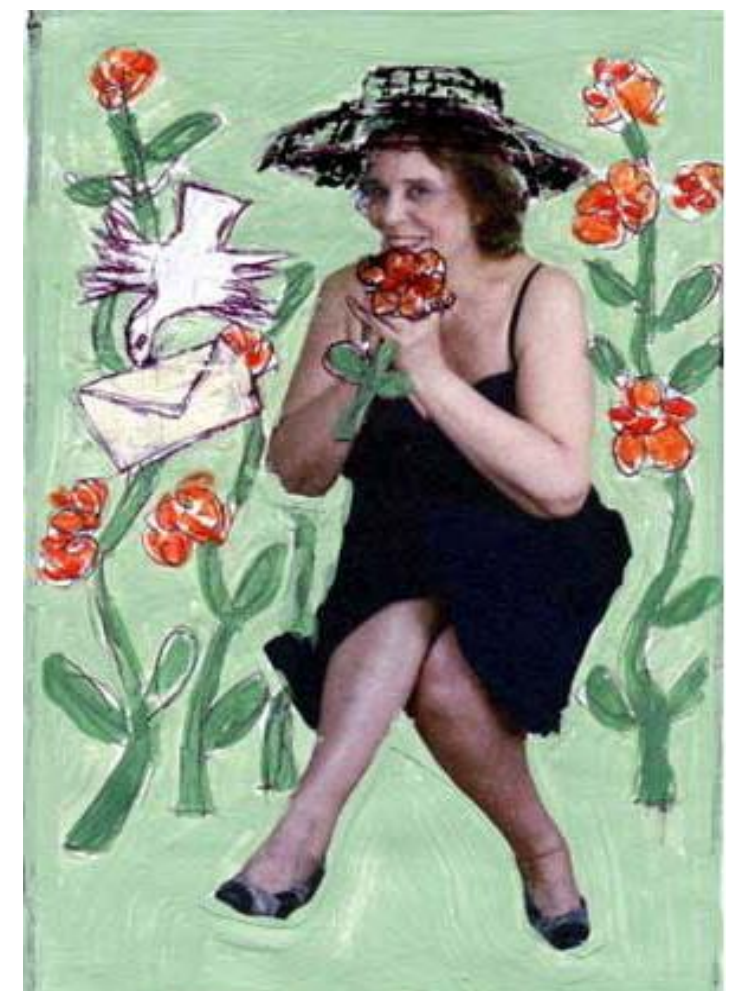

Figura 9: Zoravia Bettiol. "Namorar”. Série sentar, sentir, ser. - Fotografia e pintura acrílica, 2006. Fonte: Zoravia Bettiol (2018)

Em ambos trabalhos apresentados (do aluno e da artista), as figuras estão representadas em uma ação contemplativa, como se conseguissem suspender o tempo e o espaço, numa espécie de ócio. Desta forma, é possível pensar nas reflexões apresentadas por Duarte Jr (2010) que apontam para uma crise dos sentidos (anestesia), em que pouco tempo é destinado ao acesso do sensível. Assim, o ócio e a contemplação como forma de prazer é fonte de estesia, sem necessidade de etiqueta, como manifestação comportamental ou etiqueta como catalogação e/ou identificação.

\section{Considerações finais}

Depreende-se da análise dos dados que a aplicação da oficina propiciou que a dimensão do sensível fosse explorada e vivenciada, sendo demonstrada a capacidade interpretativa dos alunos e de letramentos complexos que, partindo de um discurso verbal, elaboram etiquetas referenciando a posição social que ocupam, lançando mão de seus conhecimentos enciclopédicos (KOCH; ELIAS, 2012).

A importância de adotar uma perspectiva de trabalho em arte/educação que propicie a reflexão de aspectos do cotidiano, em detrimento da escolha por adotar uma prática de ensino pautada apenas na apresentação das escolas e dos movimentos de história da arte, justifica-se 
através da educação do sensível em que necessitamos de uma educação crítica para as imagens.

Logo, práticas de ensino pautadas na Cultura Visual são relevantes por possibilitarem repensar a construção de valores, fazendo-se com que se reflita sobre a interferência social e cultural na construção de olhares e do quanto esses estão pautados numa lógica heteronormativa.

\section{Referências}

AROUCA, C. Arte na escola: como estimular um olhar curioso e investigativo nos alunos dos anos finais do ensino fundamental. São Paulo: Editora Anzol, 2012.

BETTIOL, Z. Reprodução da obra Namorar. Disponível em: http://www.zoraivabettiol.com.br/obras/pinturas. Acesso em: 11 abr. 2018. (Reprodução de obra artística em arquivo digital).

BUTLER, J. Problemas de gênero: feminismo e subversão da identidade. Rio de Janeiro: Civilização Brasileira, 2003.

DAYRELL, J.A escola "faz" as juventudes? Reflexões em torno da socialização juvenil. Revista Educação e sociedade [online]. 2007, vol.28, n.100, pp.1105-1128. ISSN 0101-7330. Disponível em: http://dx.doi.org/10.1590/S0101-73302007000300022. Acesso em: 11 abr. 2018. (Artigo em periódico digital).

DUARTE JR, F. O sentido dos sentidos: A educação do olhar sensível. 5 ed. Curitiba: Criar Edições LTDA, 2010.

FREEDMAN, K. Interpreting Gender and Visual Culture in Art Classrooms. Studies in Art Education, 35, 1994. p. 157-170.

FREUD, S. Algumas consequências psíquicas da distinção anatômica entre os sexos (1925). In: . Obras psicológicas completas de Sigmund Freud. Volume 19 (1923-1925). O ego e o id e outros trabalhos. São Paulo: Companhia das Letras, p. 256-271, 2010. 
FOUCAULT, M. Vigiar e punir: nascimento da prisão; tradução de Raquel Ramalhete. 41 ed. Petrópolis, RJ: Vozes, 2013.

GOLDENBERG, M. Coroas: Corpo, Envelhecimento, Casamento e Infidelidade. Rio de Janeiro: Record, 2008.

KASTRUP, V. Ensinar e aprender: falando de tubos, potes e redes. Arte na Escola, São Paulo, n.40, p.6-7, dez. 2005.

KOCH, I.; ELIAS, V. Ler e compreender: os sentidos do texto. 3 ed. São Paulo: Contexto, 2012.

LACAN, J. A significação do falo. In: LACAN, J. Escritos. Rio de Janeiro, JZE, p.692-703, 1998.

MEIRA, M. R.; PILlOTTO, S. S. D. Arte, afeto e educação: a sensibilidade na ação pedagógica. Porto Alegre, RS: Editora Mediação, 2010.

SOBRAL, A.; GIACOMELLI, K. Observações didáticas sobre a análise dialógica do discurso - ADD. Revista Domínios da Linguagem. v. 10 n. 3 (2016). Disponível em: http://dx.doi.org/10.14393/DL23-v10n3a2016-15. Acesso em: 11 abr. 2018. (Artigo em periódico digital).

SOL.

Anúncio

publicitário.

Disponível

em:

<http://sandeepmakam.blogspot.com.br/2006/11/sol-beer-from-brazil.html >. Acesso em: 11 abr. 2018. (Publicidade disponível em arquivo digital).

TILIO, R. de. Teorias de gênero: principais contribuições teóricas oferecidas pelas perspectivas contemporâneas. Revista Gênero, vol. 4. N.2, p.125-146, 1 sem de 2014. Disponível em: www.revistagenero.uff.br/index.php/revistagenero/article/view/626. Acesso em: 11 abr. 2018. 
YANGUELLO, M. Introdução. In: BAKHTIN, M. M. Marxismo e filosofia da linguagem: problemas fundamentais do método sociológico da linguagem. Tradução de Michel Laud e Yara Frateschi Vieira. 16a Edição. São Paulo: Hucitec, 2014. 